\title{
Intramolecular cyclisation of isosorbide by dimethylcarbonate chemistry
}

\author{
Pietro Tundo ${ }^{\mathrm{a}, \mathrm{b}, *}$, Fabio Aricò ${ }^{\mathrm{a}, \mathrm{b}}$, Guillaume Gauthier $^{\mathrm{c}}$, Agostino Baldacci ${ }^{\mathrm{d}}$ \\ ${ }^{a}$ Interuniversity Consortium “Chemistry for the Environment”, Via delle Industrie, 21/8 30175 Marghera, Venice, Italy \\ ${ }^{\mathrm{b}}$ Ca' Foscari Università di Venezia, Dipartimento Scienze Ambientali, Dorsoduro 2137, 30123 Venice, Italy \\ ${ }^{\mathrm{c}}$ École nationale supérieure de chimie de Paris (ENSCP - Chimie ParisTech), 11, rue Pierre-et-Marie-Curie, 75005 Paris, France \\ d Ca' Foscari Università di Venezia, Dipartimento di Chimica Fisica, Dorsoduro 2137, 30123 Venice, Italy
}

\section{A R T I C L E I N F O}

\section{Article history:}

Received 20 April 2010

Accepted after revision 25 November 2010

Available online 3 February 2011

\section{Keywords:}

Green chemistry

Carbohydrates

Cyclisation

Heterocycles

Nucleophilic substitution

\begin{abstract}
A B S T R A C T
In this work the synthesis of a tricyclic isosorbide derivative in moderate yield directly from the dicarboxymethyl isosorbide in a continuous-flow apparatus is reported. The tricyclic structure has been isolated as pure and fully characterized. This product confirms the potentiality of dimethylcarbonate (DMC) as dehydrating agent also for complicated structure and opens up further investigation and application of DMC chemistry on renewable starting materials.

(C) 2011 Académie des sciences. Published by Elsevier Masson SAS. All rights reserved.

R É S U M É

La synthèse d'un dérivé tricyclique de l'isosorbide-nouvelle démonstration de la polyvalence du diméthylcarbonate (DMC)-est ici présentée. Ce dérivé a été obtenu avec un rendement modéré, par un procédé à flux continu directement à partir du dicarboxyméthyl-isosorbide. Le composé pur a été isolé et sa structure pleinement caractérisée. Ce produit confirme la capacité du DMC à jouer un rôle d'agent déshydratant même sur des structures complexes et ouvre de nouvelles voies d'investigation visant à appliquer la chimie du DMC à la transformation de matières premières renouvelables.
\end{abstract}

(c) 2011 Académie des sciences. Publié par Elsevier Masson SAS. Tous droits réservés.
Short chain dialkylcarbonates such as dimethylcarbonate (DMC), produced nowadays by clean processes, are renowned for possessing properties of low toxicity and high biodegradability, which make them true green solvents and reagents [1]. In particular, DMC has been widely used as efficient eco-sustainable substitute of the most common carboxymethylating and methylating agents such as phosgene, methyl halides or methylsulfate that are toxic and highly corrosive [2]. DMC has shown high selectivity with different monodentate nucleophiles (alcohols, amines, thiols, $\mathrm{CH}_{2}$ acidic compounds) and bidentate nucleophiles (hydrazine) acting, at will, as methylating and/or carboxymethylating agent [3]. In general DMC reacts as carboxymethylating agent at reflux

\footnotetext{
* Corresponding author.

E-mail address: tundop@unive.it (P. Tundo).
}

temperature $\left(90^{\circ} \mathrm{C}\right)$ while it acts as methylating agent $\left(\mathrm{B}_{\mathrm{Al}} 2\right.$ mechanism) at temperatures higher than $150{ }^{\circ} \mathrm{C}$ in the presence of a base [4]. However, it was previously reported that under similar conditions the reaction of hard alkoxides with DMC gave exclusively the transesterified methylcarbonates derivatives (via $\mathrm{B}_{\mathrm{Ac}} 2$ mechanism), also at high temperatures [5]. Methyl ethers of primary alcohols can be obtained through a two steps reaction: a $\mathrm{B}_{\mathrm{Ac}} 2$ transesterification followed by the decarboxylation of the resulting methylcarbonate. Methylation of secondary and tertiary alcohols was never obtained quantitatively due to the formation of elimination products [5]. However, recently, it was reported that the secondary hydroxyl groups of isosorbide, an anhydro sugar alcohol derived from sorbitol widely used in the manufacture of polymers, are efficiently methylated at reflux temperature $\left(90^{\circ} \mathrm{C}\right)$ by reaction with DMC in the presence of a range of bases (Scheme 1). The remarkable reactivity of isosorbide 


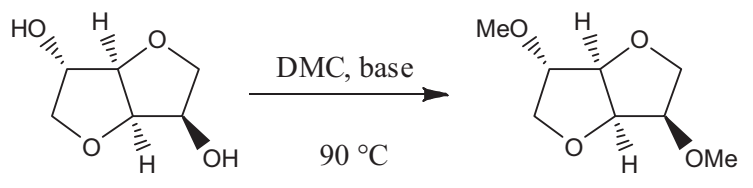

Scheme 1. Methylation of isosorbide.

towards methylation with DMC could be assigned to its unique "V"-like structure where each hydroxyl group is in the $\beta$-position to both furanic oxygens [6].

Moreover, our recent investigation on the methylation of isosorbide demonstrated that during this reaction several intermediates are also formed. In particular, three classes of compounds were identified (Fig. 1): carboxymethyl derivates (MC-1, MC-2, DC), carboxymethyl methyl derivates (MCE-1, MCE-2) and methyl derivates (MMI-1, MMI-2 and DMI). All these derivatives were isolated as pure compounds and characterized [6].

In this article we report another by-product formed during the methylation reaction of isosorbide: a tricyclic structure (Fig. 1) namely (3S,3aR,6aR)-hexahydro-3,6epoxyfuro[3,2-b]furan. This tricyclic structure was previously synthesised starting from the ditosylate derivative of isosorbide in the presence of sodium ethoxide and ethanol [7]. However, full characterization and rationalization of the product was never reported.

More importantly, this product demonstrates the potentiality of DMC as dehydrating agent for the synthesis of heterocycles by chlorine-free chemistry. In fact, the commonly used synthetic approaches for the formation of heterocycles (via cyclisation and/or cycloaddition) involve mainly chlorine chemistry at different levels e.g. activated chlorine-based leaving groups, or leaving groups created through the use of chlorine (e.g. tosylate-through the chlorosulphonation of toluene, mesylate, etc.) [8]. Moreover, cyclisation reactions conducted in acidic conditions or in the presence of chlorine derivates involve generally toxic reagents. In particular, Scheme 2 reports some possible synthetic pathways for the synthesis of heterocyclic compounds. The use of tosyl chloride or tionyl chloride (Scheme 2, path a), commonly used in the two steps of synthesis of heterocycles, requires (in the first step) the isolation of the mono tosyl (or chlorine) adduct by column chromatography. Meanwhile the DMC-mediated intramolecular cyclisation has the advantage to be a one-pot approach to heterocycles (Scheme 2, path b).

Thus, in this work it is reported the novel synthesis of tricyclic adduct of isosorbide by a green chlorine-free approach. The synthesis of this tricyclic structure is particularly relevant since it also supports a new expanding field for the chemistry of DMC: green synthesis of cyclic structure from renewable feedstock (carbohydrates). This research field has recently shown to have numerous applications in cosmetic and fragrance manufacture [9].

The formation of the tricyclic adduct of isosorbide in moderate yield (38\%) was noticed during an attempt to synthesize DMI by decarboxylation of DC in a continuous flow apparatus at high temperature using hydrotalcite KW2000 as catalyst (Scheme 3) [10].

The best conditions observed (Table 1 ) for the formation of the tricyclic adduct of isosorbide starting from DC, include high temperature $\left(200-240{ }^{\circ} \mathrm{C}\right)$ and a slow flow rate $(0.05-0.22 \mathrm{~g} / \mathrm{min})$. GC-MS analysis of the collected reaction mixture showed that it includes DMI and the tricyclic as main products together with a mixture of other methyl derivates of isosorbide. This mixture was subject to

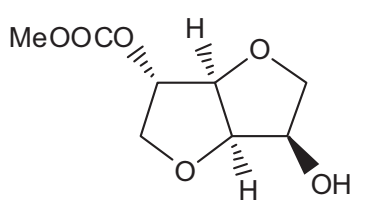

MC-1

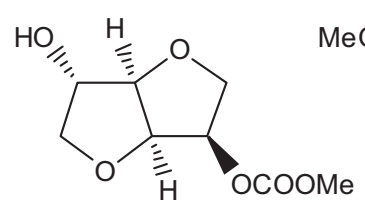

MC-2

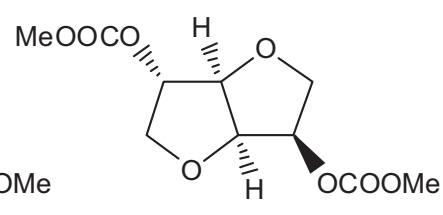

DC

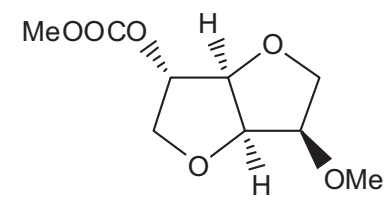

MCE-1

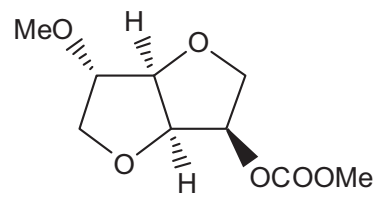

MCE-2

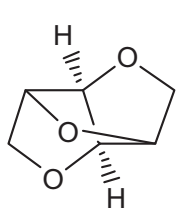

Tricyclic Adduct

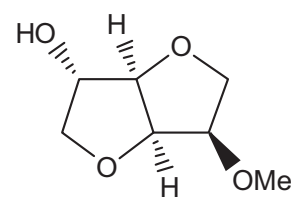

MMI-1

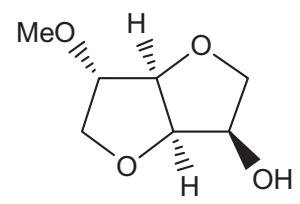

MMI-2

Fig. 1. Derivatives formed during the methylation of isosorbide. 
a<smiles>[R]C(CO)C([R])CO</smiles><smiles>[R]C(CO)C([R])C[SeH]</smiles><smiles>CC</smiles><smiles>[R]C1COCC1[R]</smiles><smiles>[R]C(CO)C([R])CCl</smiles><smiles>O[Si](Cl)(Cl)O[Na]</smiles>

b<smiles>[R]C(CO)C([R])CO</smiles>

DMC, base<smiles>[R]C1COCC1[R]</smiles>

Scheme 2. a: synthesis of cyclic ethers by two steps chlorine-based chemistry. Tosyl chloride/pyridine or thionyl chloride followed by cyclisation of the mono tosylate or mono chlorine adduct in the presence of a base. The mono tosylate and mono chlorine derivatives require purification by column chromatography; b: synthesis of cyclic ethers by one-pot DMC-mediated cyclisation.

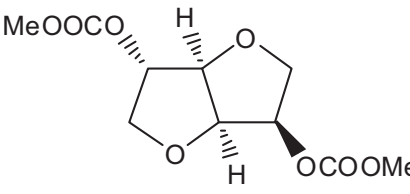

$\mathrm{DC}$

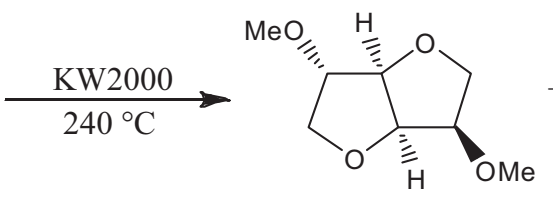

DMI

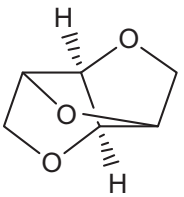

Tricyclic

Scheme 3. Synthesis of the tricyclic derivative of isosorbide.

Table 1

Synthesis of the cyclic derivative of isosorbide in Continuous-Flow conditions.

\begin{tabular}{|c|c|c|c|c|c|c|}
\hline \# & Substrate $(\mathrm{g})$ & Temp. $\left({ }^{\circ} \mathrm{C}\right)$ & Flow $(\mathrm{g} / \mathrm{min})$ & Conv. $^{\mathrm{a}}(\%)$ & DMI (\% GC-MS) & Tricyclic (\% GC-MS) \\
\hline 1 & $\mathrm{DC}(5)$ & 220 & 0.22 & 100 & 39 & 31 \\
\hline 2 & $\mathrm{DC}(5)$ & 220 & 0.22 & 100 & 25 & 26 \\
\hline 3 & $\mathrm{DC}(5)$ & 240 & 0.16 & 100 & 48 & 35 \\
\hline 4 & $\mathrm{DC}(5)$ & 240 & 0.05 & 100 & 54 & 38 \\
\hline 5 & DC (10) & 250 & 0.08 & 100 & 48 & 26 \\
\hline 6 & $\mathrm{DC}(5)$ & 260 & 0.10 & 100 & 45 & 31 \\
\hline
\end{tabular}

DC was dissolved in a mixture of toluene/hexane 65/35, Hydrotalcite KW200 (1.1 g) was used as catalyst.

a In the table are reported the GC-MS percentage only for DMI and the tricyclc derivatives, which are the main reaction products.

distillation to recover the fraction containing the tricyclic compounds. Finally the pure compound was recrystallized in hot hexane as needle-like white crystals.

Full characterization by NMR spectroscopy, GC-MS and IR analysis confirmed the proposed structure. ${ }^{1}$ In particular the comparison of IR data of the tricyclic molecule with dimethyl isosorbide (DMI), with which is strictly correlated, shows similar strong features appearing in the same

\footnotetext{
${ }^{1}$ Tricyclic adduct of isosorbide: as white crystals, C6H8O3; m.p. = 69.970.7 (C; M = 128,05 g.mol-1; $1 \mathrm{H}$ NMR $(300 \mathrm{MHz}, \mathrm{CDCl} 3)(=4.54(\mathrm{~s}, 2 \mathrm{H})$, $4.46(\mathrm{~s}, 2 \mathrm{H}), 3.98(\mathrm{~d}, 2 \mathrm{H}), 3.88(\mathrm{~s}, 2 \mathrm{H}), 4.12(\mathrm{~d}, 1 \mathrm{H}), 3.99(\mathrm{dd}, 1 \mathrm{H}), 3.88 ; 13 \mathrm{C}$ NMR $(75 \mathrm{MHz}, \mathrm{CDCl} 3)(=81.6,76.8,73.2$; IR: 750.1336, 843.4426, 902.9852, 967.4785, 1004.7522, 1062.2184, 1091.2338, 1097.5009, 1472.6070, 1507.6982, 2879.3347, 2944.7648, 2979.4821, 3014.0214.
}

spectral range blue-shifted in the $\mathrm{C}-\mathrm{H}$ stretching region and red-shifted in the fingerprint portion.

It was finally possible to grow crystals suitable for X-ray diffraction which are in accordance with the data previously collected [11].

Noteworthy, the reaction mechanism leading to this tricyclic structure is quite intriguing. In fact the reaction leading to the formation of the tricyclic is a concurrent pathway of the decarboxylation of DC to give DMI.

As reported in Scheme 4, probably, small amount of water (or methanol) in the catalyst or in the solvents can lead to the formation of the monocarboxymethyl derivatives of isosorbide MC1 and MC2. Between the two derivatives, MC1 is the only adduct that can lead to the formation of the tricyclic derivatives by a one-pot intermolecular cyclisation. This is because the endo hydroxyl moiety can backside 


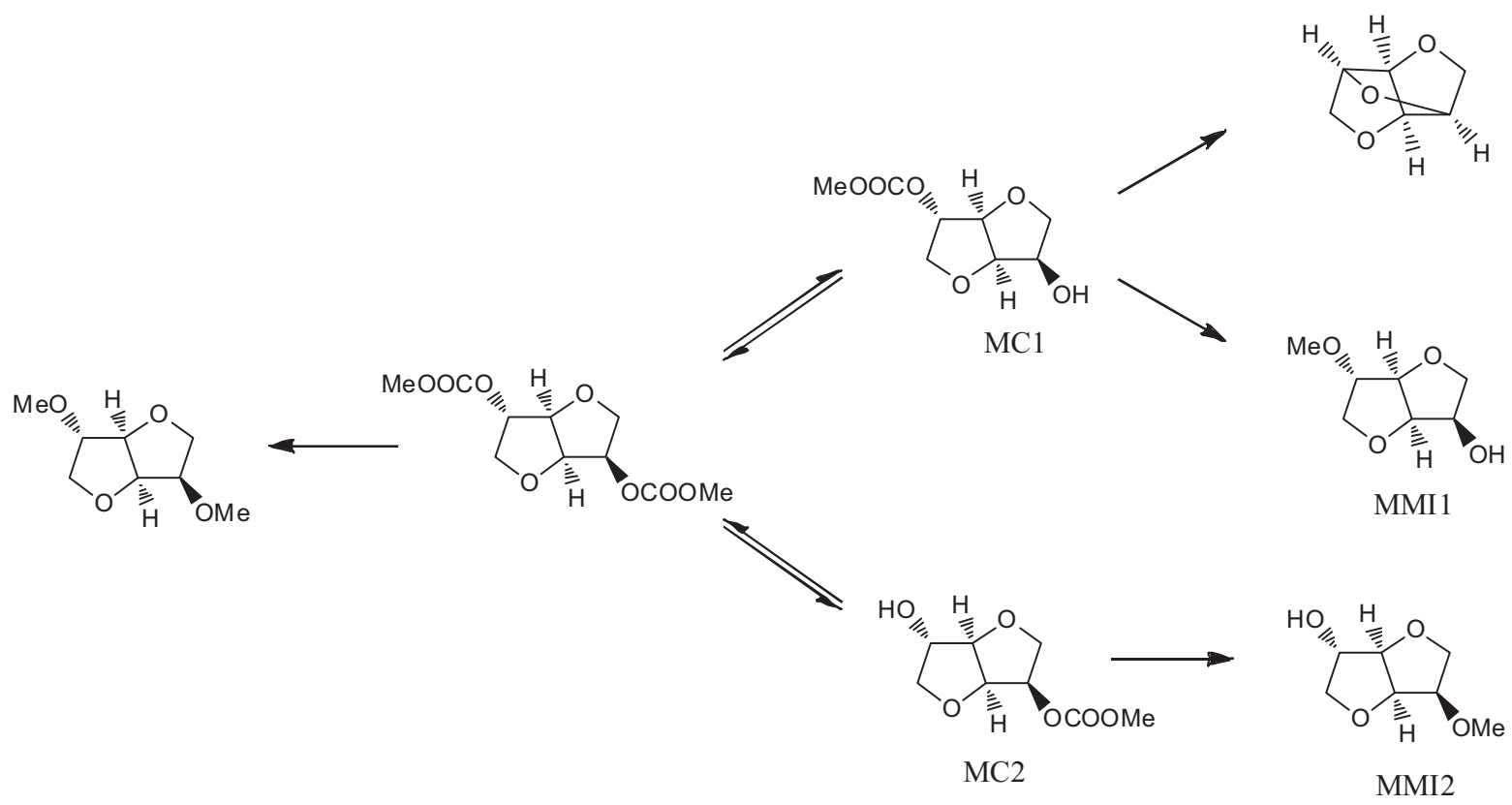

Scheme 4. Possible reaction mechanism leading to the formation of the triscyclic adduct of isosorbide.

attack the exo carboxymethyl group by intermolecular $\mathrm{S}_{\mathrm{N}} 2{ }^{2}$ $\mathrm{MC2}$, on the contrary, is sterically hindered and will lead to the formation of MMI2.

Moreover, it must be mentioned that this reaction is specific of isosorbide. In fact, isomannide and isoiodide, which are epimers of isosorbide, will not lead to the formation of such tricylic compounds since the hydroxyl groups are either both endo (isomannide) or both eso (isoiodide).

In conclusion, in this work the synthesis of a tricyclic derivate of isosorbide in moderate yield from DC and DMC in the presence of a base and employing a continuous-flow apparatus is reported. The tricylic structure has been isolated as pure and fully characterised. Moreover, the DMC-mediated cyclisation of isosorbide to achieve the tricyclic derivative does not use any toxic reagent neither lead to any harming waste. Thus, the reported synthetic procedure opens up a novel field of investigation with numerous industrial applications: the chlorine-free synthesis of heterocycles by DMC chemistry.

\section{Appendix A. Supporting information}

${ }^{1} \mathrm{H}$ NMR and ${ }^{13} \mathrm{C}$ NMR data, GS-MS analysis of the tricyclic adduct of isosorbide are available with the electronic version of this article, doi:10.1016/j.crci.2010.11.011.

\section{References}

[1] The Merck Index, 11th Ed., S. Budavari, New Jersey, USA, 1989.

[2] (a) A. Otto, J.W. Wiechers, C.L. Kelly, J. Hadgraft, J. Du Plessis, Skin Pharmacol Physiol 21 (2008) 326;

(b) E. Squillante, T. Needham, A. Maniar, S. Kislalioglu, H. Zia, Eur. J. Pharm. Biopharm 46 (1998) 265;

(c) U. Romano, F. Rivetti, N. Di Muzio, U.S. Patent 4,318,862 (1979);

(d) F. Rivetti, P. Tundo, P. Anastas (Eds.) Green Chemistry: Challenging Perspectives, Oxford University Press, Oxford, 2000, $201 \mathrm{p}$.

(e) D. Delledonne, F. Rivetti, U. Romano, J. Organomet. Chem 448 (1995) C15.

[3] P. Tundo, V. Esposito (Eds), Green Chemistry Reactions, Springer, Dordrecht, The Netherlands, 2008.

[4] P. Tundo, M. Selva, A. Perosa, S. Memoli, J. Org. Chem. 67 (2002) 1071.

[5] P. Tundo, S. Memoli, D. Hérault, K. Hill, Green Chem. 6 (2004) 609.

[6] P. Tundo, F. Aricò, G. Gauthier, L. Rossi, A.E. Rosamilia, H.S. Bevinakatti, R.L. Sievert, C.P. Newman, ChemSusChem (2010) accepted, doi: $10.1002 /$ cssc. 201000011.

[7] A.C. Cope, T.Y. Shen, J. Am. Chem. Soc. 78 (1956) 5912.

[8] (a) O. Lindner, L. Rodefeld (Eds), Benzenesulfonic Acids and Their Derivatives, Ullmann's Encyclopedia of Industrial Chemistry, WileyVCH, Weinheim, 2001;

(b) L. Cotarca, H. Eckert, Phosgenations-A Handbook, Wiley-VCH verlag GmbH \& CO. KGaA, Weinheim, Germany, 2003.

[9] H.S. Bevinakatti, C.P. Newman, S. Ellwood, P. Tundo, F. Aricò patent WO2009010791 (A2), 2009.

[10] Mg0.7Al0.301.15, specific surface area $202 \mathrm{~m} 2 / \mathrm{g}$; A sample was kindly provided by Kyowa Chemical Industry Co. Tokyo.

[11] F.W.B. Eistein, K.N. Slessor, Acta Cryst. B31 (1975) 552.

\footnotetext{
${ }^{2}$ In this case study the $\mathrm{OH}$ group labelled as endo refers to the $\mathrm{OH}$ pointing toward the isosorbide $\mathrm{V}$-shaped cavity, whilst the exo $\mathrm{OH}$ group refers to the $\mathrm{OH}$ pointing out of the $\mathrm{V}$-shaped cavity of isosorbide.
} 